\title{
ARMOURED SCALE INFESTATION OF FRUIT OF HORT16A KIWIFRUIT
}

\author{
R.H.BLANK ${ }^{1}$, G.S.C. GILL ${ }^{1}$ and K. STANNARD ${ }^{2}$ \\ ${ }^{1}$ HortResearch, Private Bag 9003, Whangarei \\ ${ }^{2}$ HortResearch, RD2, Te Puke
}

\begin{abstract}
Hort16A, Actinidia chinensis, is a new yellow-fleshed kiwifruit cultivar. Monitoring of unsprayed vines at Kerikeri and Te Puke Research Centres from 1996 to 1999 showed that armoured scale infested, on average $47 \%$ (SE \pm 0.4 ) of fruit at harvest, with an average of 11 (SE \pm 1.9 ) scale per infested fruit. Greedy scale, Hemiberlesia rapax, was the dominant species found on fruit. A survey of orchards managed using the KiwiGreen programme found five crops with 0.4$3.5 \%$ scale infested fruit, which were successfully exported. One crop which had $25 \%$ scale infested fruit was unable to be exported. Fruit rejected in the packhouse for scale were found to have an average of 28.9 scale per fruit indicating that breeding occurred on the fruit. Control of scale will be essential for the success of Hort 16A as an export crop.
\end{abstract}

Keywords: greedy scale, Hemiberlesia rapax, Hort16A, kiwifruit, Actinidia chinensis.

\section{INTRODUCTION}

Hort16A, Actinidia chinensis Planch., is a new yellow fleshed kiwifruit cultivar developed by HortResearch. Preliminary investigations indicated that Hort16A was susceptible to the major pests found on the main kiwifruit cultivar Hayward,Actinidia deliciosa (A. Chev.) C. F. Liang et A. R. Ferguson, including armoured scale. Pest control on Hort16A has been based on the current KiwiGreen programme already in use for Hayward, which allows the use of up to three organophosphate insecticides from petal fall until 2-3 months before harvest. From mid-January, sprays may only be applied if scale monitoring on leaves demonstrates a threshold is exceeded.

Greedy scale, Hemiberlesia rapax (Comstock), and latania scale, Hemiberlesia lataniae (Signoret), are the two most important and closely related species of armoured scale found on kiwifruit. Greedy scale has two generations per season on kiwifruit wood, but only a partial winter generation on leaves due to leaf abscission (Blank et al. 1996). The settled scale stages include the white cap ( $1^{\text {st }}$ instar), yellow cap ( $2^{\text {nd }}$ instar), black cap (immature $3^{\text {rd }}$ instar) and mature (reproductive $3^{\text {rd }}$ instar).

High levels of scale infestation will result in the rejection of the crop for export. Low levels of scale infestation may slow the packing of the crop, to allow scale infested fruit to be removed at the grading table, and the crop may be restricted for export to selected markets.

The main objective of this study was to quantify scale infestations on fruit of Hort16A from unsprayed vines and commercially managed orchards.

\section{Unsprayed vines}

\section{METHODS}

Fruit were sampled from a block of unsprayed Hort16A vines at the Kerikeri Research Centre which had been grafted over in 1992, and a block at the Te Puke Research Centre grafted in 1995. However, at Kerikeri two diazinon sprays were applied in 1997. Fruit were picked from ten regularly spaced vines within each block in late April and early May from 1996 to 1999 (Table 1). 


\section{Survey of commercially managed Hort16A blocks}

Fruit were picked at random from Hort16A orchards in the Whangarei and Kerikeri districts (Table 2). A total of 6 blocks of Hort16A vines, grafted between 1992 and 1996, were sampled prior to harvest in 1997 and 1998. All orchards followed the recommended KiwiGreen programme with 1 or 2 organophosphate insecticides applied in the dormant or pre-blossom period, and 2 or 3 post-blossom organophosphate insecticides applied after petal fall. The Kerikeri central orchard received dispensation for an additional post-blossom (fourth) spray. Fruit were stored at $4-9^{\circ} \mathrm{C}$ for up to 3 weeks, before being examined for scale under a microscope. Each scale cover was lifted with a pin, and stage and mortality determined. Scale species were identified as described in Blank et al. (1996).

\section{Scale infested fruit from packhouse}

Fruit rejected for export due to scale contamination were collected at a Whangarei packhouse, as lines of fruit were passing across the grading table. Samples of 20-50 reject fruit were obtained from seven commercially managed Hort16A orchards in May 1998 and 1999. All orchards followed the recommended KiwiGreen spray programme. Fruit were stored at $4-9^{\circ} \mathrm{C}$ for up to 10 weeks, before being examined for scale stage and mortality.

\section{Unsprayed vines}

\section{RESULTS}

A large proportion of fruit from the unsprayed vines at both sites was infested with scale in each growing season (Table 1). However, there was a small reduction in scale infestation levels at Kerikeri in 1997 in response to the two diazinon sprays. The overall average of scale infested fruit was $47 \%$ (SE \pm 0.4$)$. The overall average number of scale on each infested fruit was $10.7(\mathrm{SE} \pm 1.9)$. The high scale mortality was caused by the long cool storage of fruit samples before assessment (Table 1). The exception was the $17 \%$ mortality found for scale at the Kerikeri site in 1999 when fruit samples were assessed within 3 weeks of picking.

TABLE 1: Armoured scale infestation of Hort16A fruit (mean \pm SE) from unsprayed sites at harvest.

\begin{tabular}{llrrrr}
\hline Site & Year & $\begin{array}{c}\text { No. } \\
\text { Fruit }\end{array}$ & $\begin{array}{c}\text { \% infested } \\
\text { fruit }\end{array}$ & $\begin{array}{c}\text { Scale /infested } \\
\text { fruit }\end{array}$ & \% mortality \\
\hline Kerikeri & 1996 & 250 & $42 \pm 3.0$ & $11.6 \pm 2.1$ & $98 \pm 0.4$ \\
Kerikeri & $1997^{1}$ & 185 & $35 \pm 3.5$ & $5.9 \pm 0.9$ & $45 \pm 3.7$ \\
Kerikeri & 1998 & 1039 & $50 \pm 1.5$ & $10.2 \pm 0.9$ & $55 \pm 1.5$ \\
Kerikeri & 1999 & 200 & $49 \pm 3.5$ & $19.5 \pm 3.5$ & $17 \pm 2.6$ \\
Te Puke & 1997 & 1000 & $38 \pm 1.5$ & $5.1 \pm 0.5$ & $97 \pm 0.4$ \\
Te Puke & 1998 & 1250 & $56 \pm 1.4$ & $16.0 \pm 0.9$ & $95 \pm 0.2$ \\
Te Puke & 1999 & 250 & $40 \pm 3.1$ & $6.9 \pm 1.5$ & $92 \pm 1.1$ \\
\hline
\end{tabular}

${ }^{1}$ Two diazinon sprays applied.

The frequency distribution of total scale per infested fruit was similar at both sites with $27-53 \%$ singles, and the proportion of multiples declining to give a relatively small proportion of fruit with greater than 100 scale per fruit (Fig. 1). Single scale on fruit indicate a random distribution, whereas, multiple scale indicate an aggregated distribution usually due to crawlers settling in close proximity to the mother scale. Over both sites and all seasons on average $41 \%$ (SE $\pm 4 \%$ ) of infested fruit had a single scale.

The composition of scale stages varied between sites and seasons (Fig. 2). Generally, the mature scale comprised the smallest proportion of all stages, with the other stages abundant depending on the site and season. Mature scale were often surrounded by other stages on the same fruit indicating that breeding had taken place. 


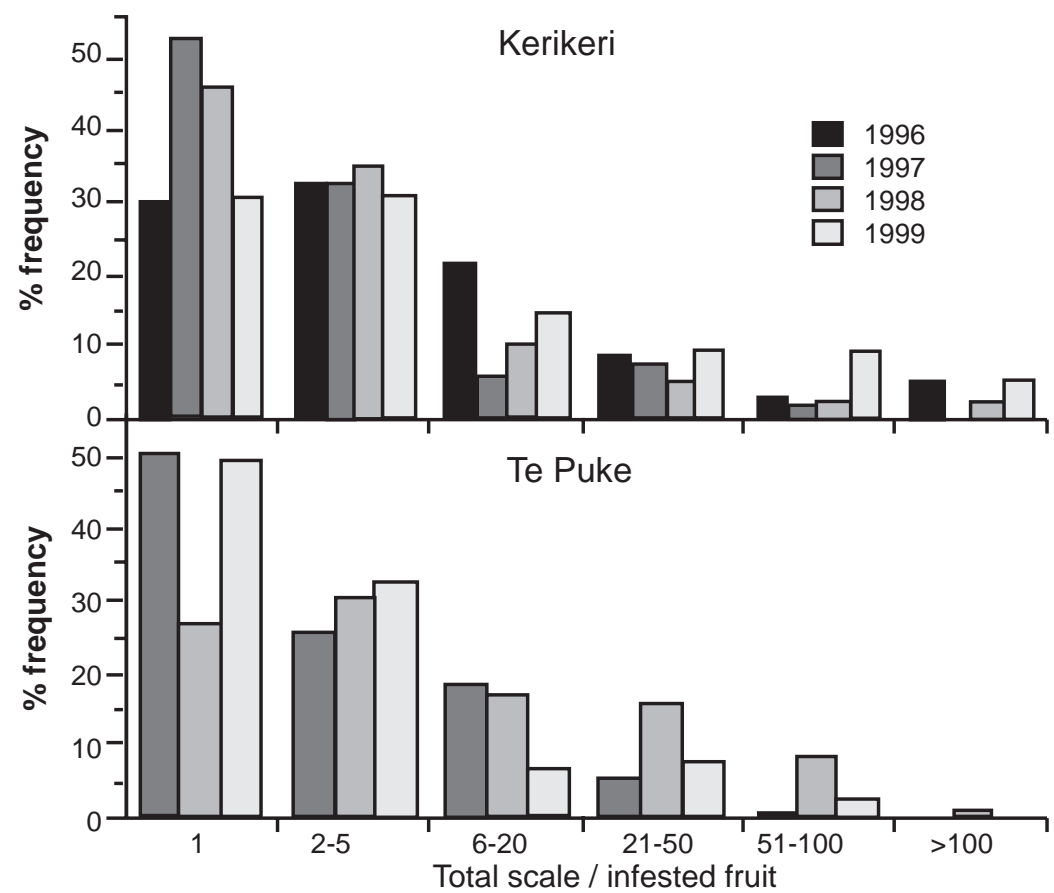

FIGURE 1: The frequency distribution of scale on fruit at harvest from unsprayed Hort16A vines at Kerikeri and Te Puke Research Centres for four and three seasons respectively.

Greedy scale were identified from $99 \%$ of the 276 mature specimens of armoured scale from fruit at the Kerikeri site and from both of the 2 specimens from the Te Puke site. Survey of commercially managed Hort16A blocks

Fruit from vines in the commercially managed orchards had lower levels of scale infestation than fruit from the unsprayed vines. The crop from the Maungatapere 1 orchard was rejected for export due to the high levels of scale found on fruit in the packhouse. Crops from the other orchards, which had 0.4-3.5\% scale infested fruit, were successfully packed for export. Multiple scale were often found on infested fruit, with 45 scale found on one fruit from the Kerikeri central orchard. Scale mortality varied from $15-100 \%$.

TABLE 2: Armoured scale infestation of Hort16A fruit (mean \pm SE) collected at random from commercially managed orchards near harvest in 1997 and 1998.

\begin{tabular}{lrrrrc}
\hline Site & Year & $\begin{array}{c}\text { No. } \\
\text { Fruit }\end{array}$ & $\begin{array}{c}\text { \% infested } \\
\text { fruit }\end{array}$ & $\begin{array}{c}\text { Scale/infested } \\
\text { fruit }\end{array}$ & \% mortality \\
\hline Maungatapere 1 & 1997 & 208 & $25.0 \pm 3.0$ & $12.1 \pm 3.0$ & $30 \pm 1.8$ \\
Maungatapere 2 & 1997 & 246 & $0.4 \pm 0.4$ & 6.0 & 100 \\
Kerikeri central & 1998 & 200 & $1.0 \pm 0.7$ & $23.0 \pm 22.0$ & $17 \pm 5.6$ \\
Kerikeri north & 1998 & 200 & $3.5 \pm 1.3$ & $4.0 \pm 2.7$ & $15 \pm 0.5$ \\
Maungatapere 2 & 1998 & 212 & $2.0 \pm 1.0$ & $1.2 \pm 0.1$ & 100 \\
Kamo & 1998 & 199 & $2.0 \pm 1.0$ & $1.0 \pm 0.1$ & $75 \pm 22$ \\
\hline
\end{tabular}




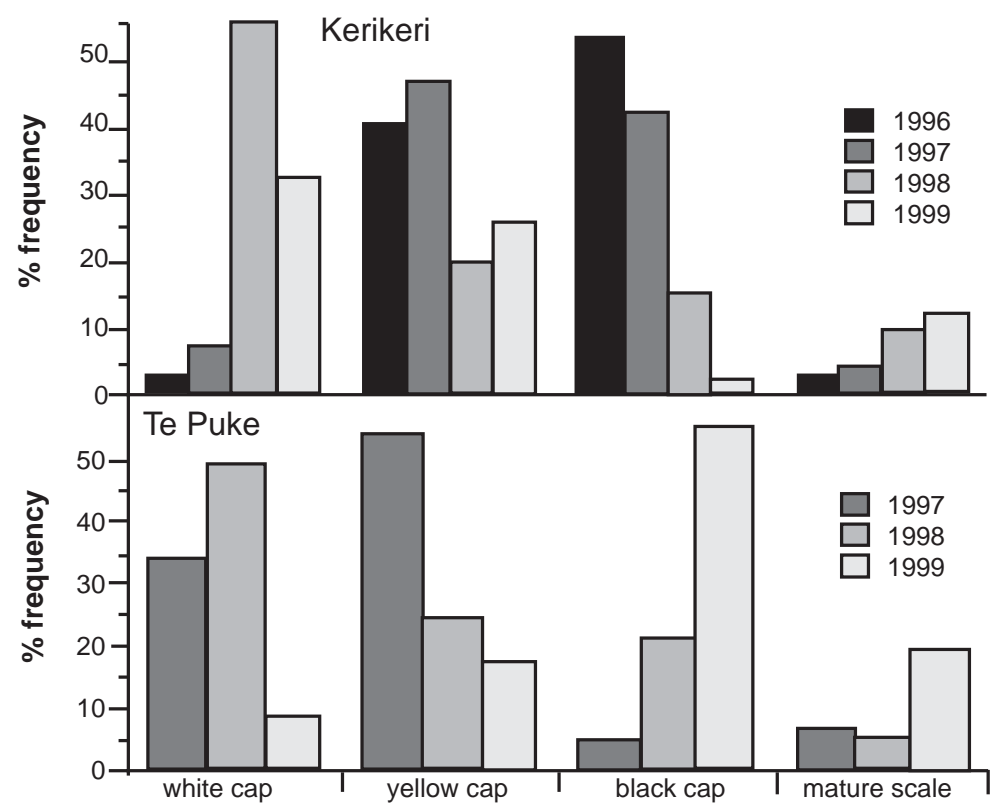

FIGURE 2: Stage composition of scale on fruit at harvest from unsprayed Hort16A vines at Kerikeri and Te Puke Research Centres for four and three seasons respectively.

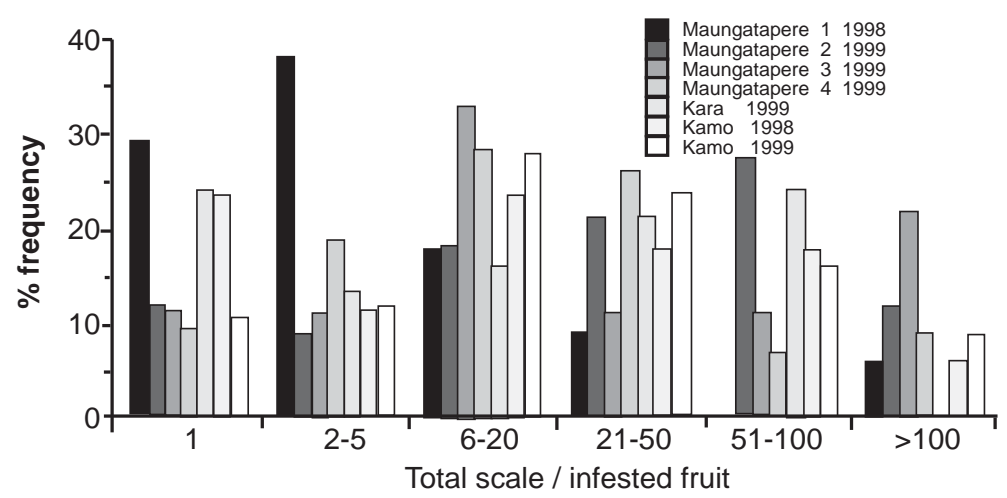

FIGURE 3: The frequency distribution of scale on fruit from seven commercially managed Hort16A orchards rejected for scale in the packhouse.

\section{Scale infested fruit from packhouse}

Fruit rejected because of scale at grading were often found to be free of scale after close examination under the microscope. On average $36 \%$ (SE $\pm 4 \%$ ) of the scale rejected fruit from the seven orchards were free of scale. Most of these fruit had either small scuffs in the skin, or were contaminated with debris (clumps of fine hairs from the brushes), or seeds or spider webbing which may have been mistaken for scale.

The frequency distribution of scale infested fruit showed that on average $83 \%$ (SE \pm 3.1 ) of the fruit had multiple scale with many having $>21$ scale / fruit (Fig. 3). There 
were on average 28.9 ( $\mathrm{SE} \pm 2.4)$ scale per infested fruit from the seven orchards, with as many as 208 scale on one fruit.

Mature scale stages were found on $96 \%$ of the fruit which had multiple scale, compared with only $36 \%$ of fruit which had single scales. The black cap stage comprised the greatest proportion of stages found on the fruit, and white caps the smallest, except for fruit with more than six scale. (Fig. 4).

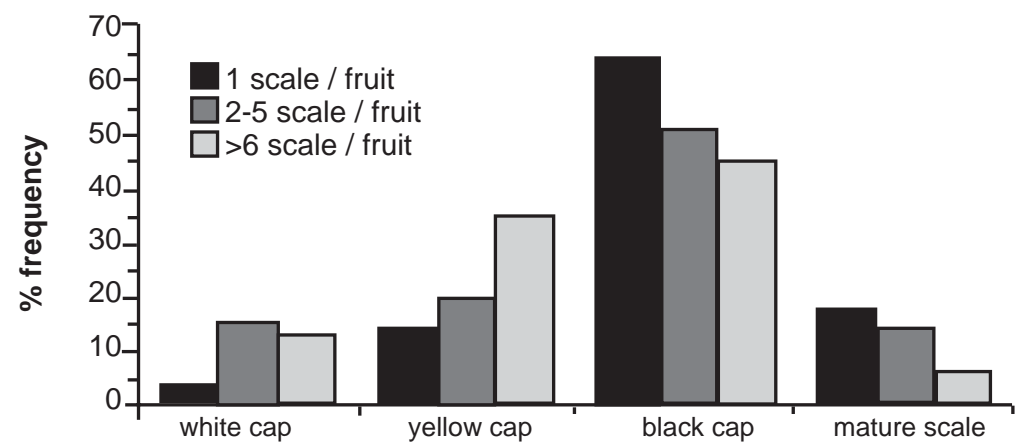

FIGURE 4: The combined stage composition of scale on fruit from seven commercially managed Hort16A orchards rejected for scale in the packhouse.

\section{DISCUSSION}

This study showed that Hort 16A fruit from unsprayed vines were heavily infested with armoured scale. Identifications found that greedy scale was the dominant species infesting fruit of Hort16A. Given that latania scale was abundant on leaves at the Kerikeri site (R.H. Blank, unpubl. data), this suggests a preference of greedy scale for Hort16A fruit. Further detailed investigations will be required to determine the scale species interactions on leaves and fruit of Hort16A. Breeding occurred readily on unsprayed fruit as evidenced by the presence of mature scale in combination with large numbers of immature stages on the same fruit.

It was of interest that both the frequency and the proportion of scale stages found on the fruit differed markedly between the unsprayed fruit and the commercially managed fruit rejected at grading for scale. The scale rejected graded fruit were infested with higher numbers of scale, and/or larger scale, than the unsprayed fruit. No comparison of numbers of scale on packhouse rejected Hort16A and Hayward fruit was made. However, the frequency distribution of scale from Hort16A fruit in this study differed from an earlier study carried out on Hayward in which single scale were found on $>60 \%$ of the scale rejected fruit and multiples were found on fewer fruit (Blank et al. 1993).

Current scale control practices, using KiwiGreen recommendations, appeared to reduce the incidence of scale to levels that are commercially acceptable. However, the control strategies did not prevent the breeding of scale on the fruit, suggesting that control of both the $1^{\text {st }}$ and $2^{\text {nd }}$ generations of scale on Hort 16 A vines may be difficult. This might be due to the difficulties in controlling two generations of scale over a long growing season with the restricted number of scalicide sprays available. Bud break and fruit set occurs approximately 30 days earlier on Hort16A than on Hayward. This will result in greater exposure of Hort16A fruit to invasion of the $1^{\text {st }}$ generation scale crawlers (Blank et al. 1996). The Hort16A fruit growing season is a month longer, which increases the risk of scale settlement and the time available for scale to breed. Options for mid to late season scale control may also be compromised, because of the lack of an approved scalicide. In addition, difficulties may be experienced in achieving complete spray coverage, because of the clumped fruiting habit of Hort16A compared to Hayward. 


\section{ACKNOWLEDGEMENTS}

We wish to thank Kiwifruit New Zealand and the Foundation for Research, Science and Technology (Contract CO6615) for financial support; the kiwifruit growers and packhouse for fruit samples; and Jean Kelly, Brya Tapper and Bridget Maher for technical support.

\section{REFERENCES}

Blank, R.H., Gill, G.S.C. and Upsdell, M.P., 1996. Greedy scale Hemiberlesia rapax (Hemiptera: Diaspididae) phenology on kiwifruit leaves and wood. N.Z. J. Crop Hort. Sc. 24: 239-248.

Blank, R.H., Olson, M.H. and Gill, G.S.C., 1993. An assessment of the quarantine risk of armoured scale (Hemiptera: Diaspididae) fruit infestations on kiwifruit N.Z. J. Crop Hort. Sc. 21: 139-145. 